\title{
BMJ Open Diabetes in pregnancy in associations with perinatal and postneonatal mortality in First Nations and non- Indigenous populations in Quebec, Canada: population-based linked birth cohort study
}

\author{
Lu Chen, ${ }^{1,2,3}$ Wen-Juan Wang, ${ }^{3,4}$ Nathalie Auger, ${ }^{5}$ Lin Xiao, ${ }^{6}$ Jill Torrie, ${ }^{7}$ \\ Nancy Gros-Louis McHugh, ${ }^{8}$ Zhong-Cheng Luo ${ }^{\oplus, 9}$
}

To cite: Chen L, Wang W-J, Auger N, et al. Diabetes in pregnancy in associations with perinatal and postneonatal mortality in First Nations and non-Indigenous populations in Quebec, Canada: population-based linked birth cohort study. BMJ Open 2019;9:e025084. doi:10.1136/ bmjopen-2018-025084

- Prepublication history for this paper is available online To view these files, please visit the journal online (http://dx.doi. org/10.1136/bmjopen-2018025084).

LC and W-JW contributed equally.

Received 29 June 2018 Revised 8 January 2019 Accepted 12 February 2019

Check for updates

(c) Author(s) (or their employer(s)) 2019. Re-use permitted under CC BY-NC. No commercial re-use. See rights and permissions. Published by BMJ.

For numbered affiliations see end of article.

Correspondence to Dr Zhong-Cheng Luo; zcluo@lunenfeld.ca

\section{ABSTRACT}

Objective Both pregestational and gestational diabetes mellitus (PGDM, GDM) occur more frequently in First Nations (North American Indians) pregnant women than their non-Indigenous counterparts in Canada. We assessed whether the impacts of PGDM and GDM on perinatal and postneonatal mortality may differ in First Nations versus non-Indigenous populations.

Design A population-based linked birth cohort study.

Setting and participants 17090 First Nations and 217760 non-Indigenous singleton births in 1996-2010, Quebec, Canada.

Main outcome measures Relative risks (RR) of perinatal and postneonatal death. Perinatal deaths included stillbirths and neonatal ( $0-27$ days of postnatal life) deaths; postneonatal deaths included infant deaths during 28-364 days of life.

Results PGDM and GDM occurred much more frequently in First Nations (3.9\% and $10.7 \%$, respectively) versus non-Indigenous ( $1.1 \%$ and $4.8 \%$, respectively) pregnant women. PGDM was associated with an increased risk of perinatal death to a much greater extent in First Nations ( $\mathrm{RR}=5.08[95 \% \mathrm{Cl} 2.99$ to 8.62], $\mathrm{p}<0.001$; absolute risk $(\mathrm{AR})=21.6[8.6-34.6]$ per 1000) than in nonIndigenous populations $(\mathrm{RR}=1.76[1.17,2.66], \mathrm{p}=0.003$; $\mathrm{AR}=4.2[0.2,8.1]$ per 1000). PGDM was associated with an increased risk of postneonatal death in nonIndigenous ( $R R=3.46[1.71,6.99], p<0.001 ; A R=2.4[0.1$, 4.8] per 1000) but not First Nations ( $R R=1.16[0.28,4.77]$, $\mathrm{p}=0.35$ ) infants. Adjusting for maternal and pregnancy characteristics, the associations were similar. GDM was not associated with perinatal or postneonatal death in both groups.

Conclusions The study is the first to reveal that PGDM may increase the risk of perinatal death to a much greater extent in First Nations versus non-Indigenous populations, but may substantially increase the risk of postneonatal death in non-Indigenous infants only. The underlying causes are unclear and deserve further studies. We speculate that population differences in the quality of glycaemic control in diabetic pregnancies and/or genetic
Strengths and limitations of this study

- A large population-based linked birth cohort study.

- The first study to reveal that pregestational diabetes mellitus may increase the risk of perinatal death to a much greater extent in First Nations than non-Indigenous populations, but increase the risk of postnenatal death in non-Indigenous infants only in Quebec, Canada.

- Lack of data on maternal smoking and obesity, but this would unlikely to have affected the comparisons within First Nations or non-Indigenous group.

- Lack of data on glycaemic control in diabetic pregnancies.

- More studies in other regions/populations are required to understand the generalisability of the study findings.

vulnerability to hyperglycaemia's fetal toxicity may be contributing factors.

\section{BACKGROUND}

Diabetes in pregnancy includes pregestational diabetes mellitus (PGDM) and gestational diabetes mellitus (GDM), ${ }^{1}$ and both affect a much greater proportion of First Nations (North American Indians) than their non-Indigenous counterparts in North America. ${ }^{2-8}$ Both PGDM and GDM have been associated with increased risks of perinatal death, birth defects, preterm birth and macrosomia, and the risk elevations are more pronounced in PGDM. ${ }^{8-17}$ Compared with non-Indigenous populations, First Nations are at 2-4 times higher risks of PGDM and GDM,${ }^{18} 19$ and 1.5-4.2 times higher risks of perinatal and postneonatal death in Quebec, Canada. ${ }^{20} 21$ 
The higher perinatal mortality and postnatal mortality rates in First Nations could be partly explained by poorer socioeconomic status. ${ }^{21}$ However, it is unknown whether the impacts of diabetes in pregnancy per se on offspring's survival may differ in such an Indigenous population with high burdens of PGDM and GDM compared with their non-Indigenous counterparts. In a large population-based linked birth cohort, we tested the hypothesis that there may be greater impacts of diabetes in pregnancy on the risks of perinatal and postneonatal death in First Nations versus non-Indigenous populations in Quebec. The hypothesis is plausible considering that the quality of glycaemic control in diabetic pregnancies may be poorer in socioeconomically disadvantaged First Nations versus non-Indigenous populations. ${ }^{19}$ Poor glycaemic control may lead to less healthy fetus and hence greater risk of death during the perinatal and/or postneonatal period.

\section{METHODS}

\section{Study design and population}

This was a population-based retrospective birth cohort study, using the linked birth and infant death database of the Institut de la Statistique du Québec (ISQ) for singleton births in Quebec, Canada, 1996-2010. ${ }^{21}$ The validity of the Canadian vital records linkage has been well documented. ${ }^{22}$ We further linked birth records to pregnancy complications through the mother's medical insurance number. ${ }^{23}$ The research protocol was approved by the ISQ, the Commission for Access to Information in Quebec, and major Indigenous community health organisations in Quebec - the Cree Board of Health and Social Services of James Bay, the First Nations of Quebec and Labrador Health and Social Service Commission, and the Nunavik Regional Board of Health and Social Services. In adherence to ISQ data confidentiality rules, all numbers are rounded to the nearest 10 .

Indigenous (First Nations, Inuit) births were identified based on three sources of information: mother tongue, community of residence (to identify Indigenous reserves according to residential postal code/municipality name) and Indian Registration System membership status of both parents (a positive in any Indigenous identifier was considered Indigenous). ${ }^{21}$ The original study cohort included 20190 First Nations, 4260 Inuit and 229960 non-Indigenous singleton births at gestational age $\geq 20$ weeks. The present study included 17090 First Nations and 217760 non-Indigenous births at $\geq 24$ weeks of gestation with linked data available on both pregnancy complications and fetus/infant's survival status from birth to 364 days of life. We restricted the analyses to births at $\geq 24$ weeks of gestation because GDM is routinely screened and diagnosed at 24-28 weeks of gestation. Inclusion of births at $<24$ weeks of gestation could introduce an immortal bias (all perinatal and postnatal deaths would not happen to the offspring of GDM women due to the absence of screening diagnosis). We focused on the comparisons of First Nations with non-Indigenous births, since First Nations (but not Inuit) women are known to be at substantially higher risk of PGDM and GDM than non-Indigenous women in Quebec. ${ }^{19}$ Exploratory analyses confirmed that Inuit women were not at higher risk of diabetes in pregnancy than non-Indigenous women. Inuit births were excluded from the present study.

\section{Linkage to pregnancy complications}

In Quebec, each resident has a lifetime unique Régie de l'Assurance Maladie du Québec (RAMQ) (Quebec health insurance) number. The mother's RAMQ number was used to link pregnancy complications (diabetes, etc) to each birth record, based on delivery discharge medical records in the provincial Maintenance et Exploitation des Données pour l'Étude de la Clientèle Hospitalière database. ${ }^{23}$ The data linkage used the hospitalisation/ diagnostic records throughout the course of the index pregnancy (based on the infant's date of birth and gestational age at delivery). The linkage to hospitalisation records was successful for 97.9\% First Nations, 92.3\% Inuit and $98.0 \%$ non-Indigenous infants. ${ }^{23}$

Pregnancy complications were coded according to the International Classification of Diseases Clinical Modification (ICD-9CM) codes in Quebec for records in the years 1996-2005, and the ICD-10 codes in Quebec for records in the years 2006-2010. In the ICD-9CM, PGDM was coded as '648.0' or '250.*', while GDM was coded as '648.8'. In the ICD-10, PGDM was coded as 'O24.5', 'O24.6', 'O24.7', 'E10' and 'E11', while GDM was coded as 'O24.8'. We did not make a distinction between different types of PGDM (type 1, type 2, other), because available information is insufficient for records based on the ICD-9CM codes in the years 1996-2005, while the numbers of records based on the ICD-10 codes in the years 2006-2010 only were too small in First Nations for such subgroup analyses on the risks of perinatal and postneonatal death.

During the study period (1996-2010), universal screening for GDM was in place in Quebec, following a two-step screening procedure. First, all pregnant women underwent a $50 \mathrm{~g} 1$ hour oral glucose challenge test at 24-28 weeks of gestation. If blood glucose was $\geq 7.8 \mathrm{mmol} / \mathrm{L}$, the $75 \mathrm{~g} 2$ hours oral glucose tolerance test was then administered. GDM was diagnosed if two of three values equaled or exceeded the following cut-offs: fasting $5.3 \mathrm{mmol} / \mathrm{L}$, 1 hour $10.0 \mathrm{mmol} / \mathrm{L}, 2$ hours $8.6 \mathrm{mmol} / \mathrm{L}^{24}$

\section{Outcomes}

The primary outcomes were perinatal death (stillbirth [fetal deaths $\geq 500 \mathrm{~g}$ ] plus neonatal death [died in the first 28 days after birth] $)^{25}$ and postneonatal death (died between 28 and 364 days after birth). These are objective outcomes not subjecting to misclassifications. We used perinatal death as a primary outcome because it is not affected by variations in registration practices in cases of deaths of newborns at the borderline of viability (a dead newborn may be registered as a stillbirth or neonatal death). ${ }^{25}$ We used postneonatal death as a primary outcome to reflect the potential 'long-term' 
impact of intrauterine exposure to diabetes on infant health. Other outcomes include birth defects, preterm ( $<37$ completed weeks of gestation), small for gestational age (SGA, <10th percentile in birth weight for sex and gestational age, according to the Canadian fetal growth standards ${ }^{26}$ ) and large for gestational age (LGA, >90th percentile) births. Birth defects included any congenital anomalies according to the ICD-9 codes (for records in 1996-2005) or ICD-10 codes (for records in 2006-2010) on birth registration and infant hospitalisation records in the first year of life. We presented the results on the total birth cohort only (rather than further stratification by year period) since the numbers of events (the primary outcomes: perinatal and postneonatal deaths) were relatively small for First Nations with PGDM or GDM.

\section{Statistical analysis}

Crude relative risks (RR) and absolute risk (AR) with 95\% CIs were calculated to illustrate the strength of the associations of PGDM and GDM with adverse birth outcomes, perinatal and postneonatal mortality. Log-binomial models were fitted to estimate the adjusted RRs with $95 \%$ CIs accounting for cluster effects (in cases of multiple births to the same mother) in generalised estimating equations. We examined the changes in the adjusted RRs to assess whether the associations of diabetes in pregnancy with perinatal and postneonatal mortality could be explained by maternal characteristics (age $[<20,20-34$, 35 +years], education $[<$ high school, high school, college, university], marital status [married, common-law union, single/separated/divorced], parity [primiparous: yes/ no], rural residence [yes/no]) and other pregnancy complications (chronic hypertension, heart disease, renal disease, genitourinary infections, anaemia, gestational hypertension and pre-eclampsia). All data analyses were carried out using SAS, V.9.2. Two-tailed $p$ values $<0.006$ were considered statistically significant, considering eight primary comparisons of interest (PGDM or GDM versus non-diabetic pregnancies in First Nations and non-Indigenous populations, two primary outcomes, $2 * 2 * 2=8$ comparisons, Bonferroni corrected $\mathrm{p}$ value cut-off $=0.05 / 8=0.006)$.

\section{Patient and public involvement}

Patients were not involved in the study based on anonymised linked birth data.

\section{RESULTS}

Of the 234850 singleton births in the study cohort (17090 First Nations, 217760 non-Indigenous), 3020 (1.3\%) were complicated by PGDM, and $12110(5.1 \%)$ by GDM. Both PGDM and GDM were much more frequent in First Nations $(3.9 \%$ and $10.7 \%$, respectively) than non-Indigenous $(1.1 \%$ and $4.8 \%$, respectively) pregnant women (table 1). Similarly, other major pregnancy complications were all substantially more frequent in First Nations versus non-Indigenous pregnant women, including chronic hypertension, gestational hypertension and pre-eclampsia, heart disease, renal disease, genitourinary infections and anaemia. Maternal characteristics differed substantially between First Nations and non-Indigenous births. Compared with non-Indigenous mothers, First Nation mothers were much more likely to be under 20 years of age $(21.9 \%$ vs $3.3 \%)$, and to live without a partner (neither married nor in a common-law union) $(26.5 \%$ vs $8.1 \%)$, but less likely to be primiparous ( $40.8 \%$ vs $46.6 \%$ ). First Nation mothers had much lower average educational attainment. About $41.6 \%$ of First Nations mothers had not completed high school-which was four times as frequent as non-Indigenous mothers (10.3\%).

PGDM was associated with over twofold greater risks of preterm birth, LGA and birth defects in both First Nations and non-Indigenous infants (table 2). Both PGDM and GDM were associated with a decreased risk of SGA to a greater extent in First Nations births than in non-Indigenous births. The RR increases in LGA were greater for PGDM than for GDM in both groups. PGDM was associated with an increased risk of perinatal death to a much greater extent in First Nations (RR 5.08 [95\% CI 2.99 to 8.62], $\mathrm{p}<0.001$; AR 21.6 [8.6-34.6] per 1000) than in non-Indigenous ( $R R$ 1.76 [1.17, 2.66], $\mathrm{p}=0.003$; AR 4.2 $[0.2,8.1]$ per 1000) births. However, PGDM was associated with a substantially increased risk of postneonatal death in non-Indigenous infants (RR 3.46 [1.71, 6.99]; AR $2.4[0.1,4.8]$ per 1000$)$, but was not associated with postneonatal death in First Nations infants (RR 1.16, $\mathrm{p}=0.35$ ). GDM was associated with a marginally lower risk of perinatal death in non-Indigenous births only (RR 0.72 [0.53, $0.98]$ ), but the association would become non-significant if accounting for multiple tests $(\mathrm{p}=0.02)$. GDM was not associated with postneonatal death in both First Nations and non-Indigenous infants. PGDM was associated with over twofold increased risk of birth defects in both First Nations and non-Indigenous births, while GDM was not associated with a significantly higher risk of birth defects in both groups.

Table 3 presents the adjusted RRs comparing PGDM or GDM to non-diabetic pregnancies. Compared with the crude RRs, the RRs adjusting for mother-level cluster effects only changed little $(<10 \%)$ for all outcomes. With further adjustment for maternal characteristics (age, education, marital status, parity and rural residence), the risk disparities comparing PGDM versus non-diabetic pregnancies changed little for perinatal death in both First Nations (RR: fluctuated around 5) and non-Indigenous (RR: fluctuated around 1.8) infants. PGDM was associated with about 3.5 times increased risk of postneonatal death in non-Indigenous infants regardless of various adjustments, while there was no risk increase in First Nations infants. Further adjusting for other maternal illnesses, the RRs comparing PGDM versus non-diabetic pregnancies decreased substantially for preterm birth in both First Nations (RR: from 2.25 to 1.30) and non-Indigenous (RR: from 2.15 to 1.46 ) groups, and for birth defects in First Nations (RR: from 
Table 1 Maternal and pregnancy characteristics of First Nations and non-Indigenous singleton births in Quebec 1996-2010

\begin{tabular}{|c|c|c|c|}
\hline Characteristic & $\begin{array}{l}\text { First Nations } \\
(n=17090)\end{array}$ & $\begin{array}{l}\text { Non-Indigenous } \\
(\mathrm{n}=217760)\end{array}$ & P value ${ }^{*}$ \\
\hline Maternal age (year) & $25.1(6.2)$ & $28.8(5.2)$ & $<0.0001$ \\
\hline$<20$ & 21.9 & 3.3 & $<0.0001$ \\
\hline $20-34$ & 69.5 & 82.6 & \\
\hline$\geq 35$ & 8.6 & 14.1 & $<0.0001$ \\
\hline Maternal education (year) & $11.1(3.1)$ & $13.9(3.1)$ & $<0.0001$ \\
\hline$<$ Highschool & 41.6 & 10.3 & $<0.0001$ \\
\hline High school (11 y) & 22.2 & 15.2 & \\
\hline College (12-13 y) & 15.0 & 16.1 & \\
\hline University (14+y) & 21.2 & 58.3 & \\
\hline Marital status (\%) & & & $<0.0001$ \\
\hline Married & 21.7 & 40.6 & \\
\hline Common-law union & 51.8 & 51.4 & \\
\hline Single, divorced, widowed & 26.5 & 8.1 & \\
\hline Primiparous (\%) & 40.8 & 46.6 & $<0.0001$ \\
\hline Rural residence (\%) & 75.6 & 15.6 & $<0.0001$ \\
\hline \multicolumn{4}{|l|}{ Diabetes in pregnancy (\%) } \\
\hline Pregestational diabetes & 3.9 & 1.1 & $<0.0001$ \\
\hline Gestational diabetes & 10.7 & 4.8 & $<0.0001$ \\
\hline \multicolumn{4}{|l|}{ Other complications (\%) } \\
\hline Chronic hypertension & 1.3 & 0.7 & $<0.0001$ \\
\hline Gestational hypertension & 8.0 & 4.3 & $<0.0001$ \\
\hline Pre-eclampsia & 3.5 & 1.5 & $<0.0001$ \\
\hline Heart disease & 0.6 & 0.4 & 0.0375 \\
\hline Renal disease & 4.0 & 2.7 & $<0.0001$ \\
\hline Genitourinary infections & 3.9 & 2.5 & $<0.0001$ \\
\hline Anaemia & 22.2 & 12.6 & $<0.0001$ \\
\hline Infant sex, male & 51.7 & 51.2 & 0.2095 \\
\hline
\end{tabular}

Data presented are \% or mean (SD).

${ }^{*} \mathrm{P}$ values for comparisons between First Nations and non-Indigenous groups.

1.78 to 1.34 ) and non-Indigenous (RR: from 2.22 to 1.52) groups. The RRs for LGA changed little comparing PGDM or GDM versus non-diabetic pregnancies in both First Nations and non-Indigenous infants with various adjustments.

\section{DISCUSSION}

\section{Main findings}

Our study is the first to reveal differential associations of PGDM with perinatal and postneonatal mortality in Indigenous versus non-Indigenous populations. PGDM was associated with a much greater elevated risk of perinatal death in First Nations than in non-Indigenous populations, but was associated with a substantially elevated risk of postneonatal death in non-Indigenous infants only.
Data interpretation and comparisons with findings in previous studies

First Nations are a high-risk population for diabetes. ${ }^{27}$ As expectedly, our data revealed over three times increased risk of PGDM and over two times increased risk of GDM in First Nations versus non-Indigenous populations in Quebec.

Our study is the first to reveal that the risk elevation in perinatal death for PGDM was to a much greater extent in First Nations (5.1-fold) than non-Indigenous (1.8-fold) populations. Glycaemic control tends to be worse in First Nations than non-Indigenous patients with diabetes. ${ }^{28}$ Poor glycaemic control has been linked to perinatal death. ${ }^{29} 30$ This may partly explain the greater risk elevation in perinatal death for PGDM pregnancies in First Nations. Poorer glycaemic control may result in more frequent unhealthy fetuses, and consequently more 


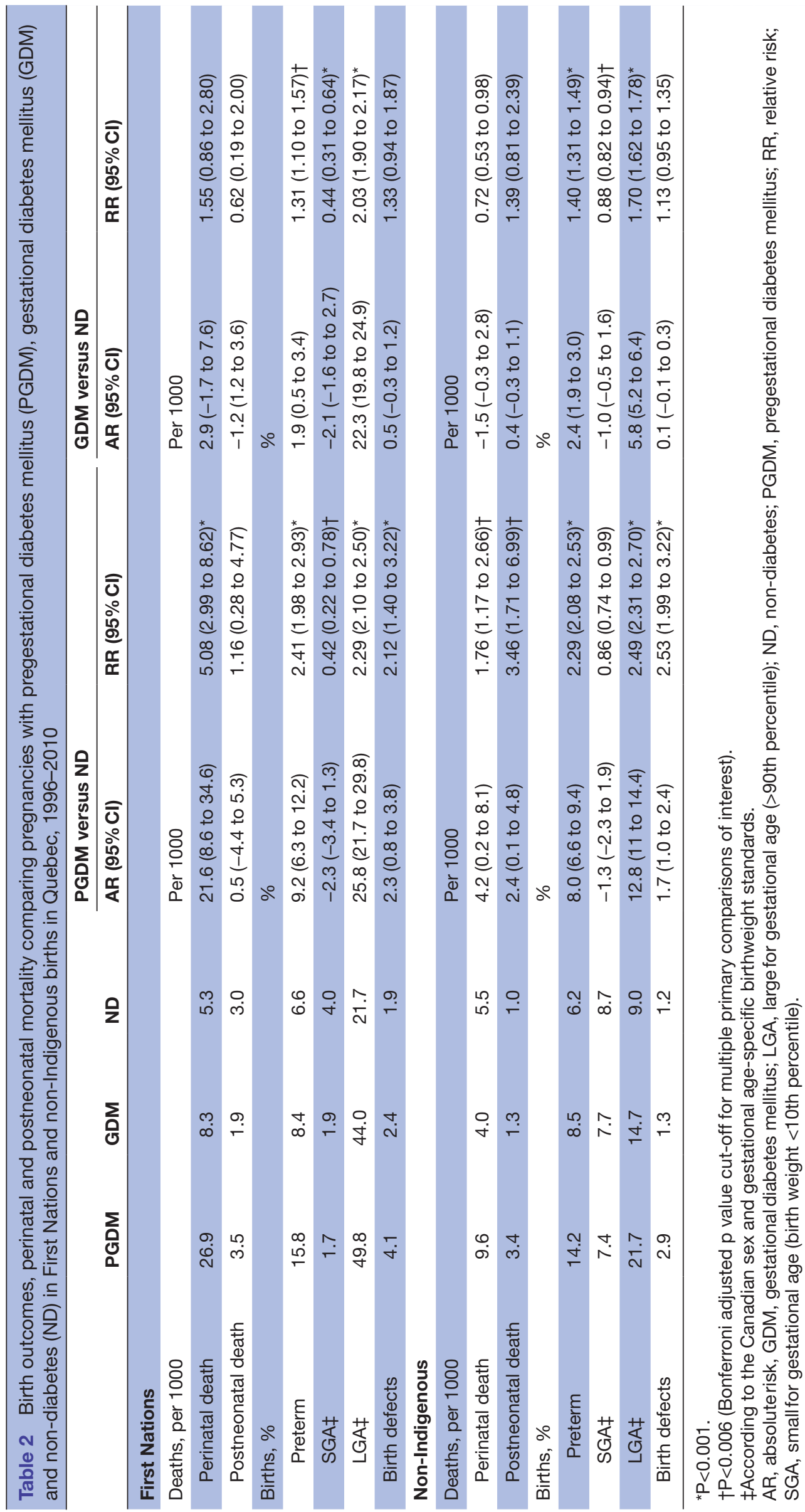


Table 3 Adjusted relative risks (RRs) of birth outcomes, perinatal and postneonatal mortality comparing pregestational diabetes mellitus (PGDM), gestational diabetes mellitus (GDM) to non-diabetic (ND) pregnancies

\begin{tabular}{|c|c|c|c|c|c|c|}
\hline & \multicolumn{3}{|l|}{ PGDM versus ND } & \multicolumn{3}{|l|}{ GDM versus ND } \\
\hline & Model 1 & Model 2 & Model 3 & Model 1 & Model 2 & Model 3 \\
\hline & RR (95\% Cl) & RR (95\% Cl) & RR $(95 \% \mathrm{Cl})$ & RR (95\% Cl) & RR (95\% Cl) & RR $(95 \% \mathrm{Cl})$ \\
\hline Perinatal death & $5.15(2.97 \text { to } 8.92)^{\star}$ & $4.83(2.45 \text { to } 9.52)^{\star}$ & $4.96(2.46 \text { to } 9.99)^{*}$ & 1.55 (0.86 to 2.81$)$ & 1.45 (0.70 to 3.01$)$ & $1.48(0.71$ to 3.08$)$ \\
\hline Postneonatal death & 1.11 (0.27 to 4.60$)$ & 1.30 (0.30 to 5.61$)$ & 1.19 (0.27 to 5.24$)$ & 0.62 (0.19 to 2.00$)$ & 0.73 (0.22 to 2.41$)$ & 0.69 (0.21 to 2.31$)$ \\
\hline Preterm & $2.47(1.91 \text { to } 3.19)^{\star}$ & $2.25(1.83 \text { to } 2.77)^{\star}$ & $1.30(0.93$ to 1.81$)$ & 1.35 (1.12 to 1.64$) \dagger$ & $1.28(1.04$ to 1.57$) \ddagger$ & $1.19(0.96$ to 1.46$)$ \\
\hline LGA & $2.26(2.05 \text { to } 2.49)^{*}$ & $2.07(1.87 \text { to } 2.29)^{\star}$ & $2.06(1.85 \text { to } 2.29)^{\star}$ & $2.02(1.89 \text { to } 2.16)^{*}$ & $1.97(1.84 \text { to } 2.12)^{\star}$ & $1.94(1.80 \text { to } 2.09)^{*}$ \\
\hline Birth defects & $1.93(1.48 \text { to } 2.51)^{*}$ & $1.78(1.35 \text { to } 2.35)^{\star}$ & 1.34 (0.92 to 1.94$)$ & $1.24(1.02$ to 1.51$) \ddagger$ & 1.21 (0.99 to 1.49$)$ & 1.18 (0.96 to 1.46$)$ \\
\hline \multicolumn{7}{|l|}{ Non-Indigenous } \\
\hline Perinatal death & $1.75(1.15$ to 2.64$) \dagger$ & $1.82(1.15$ to 2.88$) \ddagger$ & 1.75 (1.11 to 2.77$) \ddagger$ & $0.72(0.53$ to 0.98$) \ddagger$ & 0.75 (0.53 to 1.06$)$ & 0.74 (0.52 to 1.05$)$ \\
\hline Postneonatal death & $3.53(1.74$ to 7.17$) \dagger$ & $3.54(1.73$ to 7.21$) \dagger$ & $3.42(1.67$ to 7.00$) \dagger$ & $1.40(0.81$ to 2.41$)$ & 1.47 (0.85 to 2.54$)$ & 1.45 (0.84 to 2.50$)$ \\
\hline Birth defects & $2.41(1.88 \text { to } 3.09)^{\star}$ & $2.22(1.65 \text { to } 2.99)^{\star}$ & $1.52(1.29 \text { to } 1.79)^{\star}$ & 0.96 (0.88 to 1.04$)$ & 0.96 (0.88 to 1.05$)$ & $0.96(0.88$ to 1.05$)$ \\
\hline
\end{tabular}

Model 1: RR adjusted for cluster effects (multiple infants of the same mother) only; model 2: model 1 plus further adjusted for maternal age, education, marital status, parity and rural residence; model 3: model 2 plus further adjusted for chronic hypertension, heart disease, renal disease, genitourinary infection, anaemia and gestational hypertension and pre-eclampsia. Infant sex and year of birth were not included in the adjustment models since they were balanced between comparison groups (all $\mathrm{p}>0.2$ ) and did not affect the comparisons.

${ }^{*} \mathrm{P}<0.001$.

$\dagger \mathrm{P}<0.006$ (Bonferroni adjusted $\mathrm{p}$ value cut-off for multiple primary comparisons of interest). $\ddagger 0.006 \leq \mathrm{p}<0.05$.

LGA, large for gestational age; SGA, small for gestational age.

perinatal deaths. However, there was a large risk increase (3.5-fold) in postneonatal death in PGDM pregnancies in non-Indigenous infants, in contrast to the absence of risk increase in First Nations infants, contradicting the hypothesis of more frequent 'unhealthy fetuses' in First Nations diabetic pregnancies. We speculated that there may be genetic difference in the vulnerability to the long-term adverse impact of fetal hyperglycaemia in First Nations versus non-Indigenous populations. Alternatively, we speculated that this may be due to a 'delayed' impact of diabetes from perinatal to postneonatal periods in non-Indigenous infants. Better glycaemic control in PGDM pregnancies might have delayed the impact into the postneonatal period in non-Indigenous population. It should be noted that the higher RR of postneonatal death associated with PGDM in non-Indigenous infants was almost entirely attributable to a much lower postneonatal mortality rate in the non-diabetic group; postneonatal mortality rates in the PGDM group were very similar in First Nations (3.5 per 1000) and non-Indigenous (3.4 per 1000) infants. It appeared that infants of mothers with non-diabetic or healthy pregnancies were the ones to benefit from the more advantageous socioeconomic and infant care conditions in non-Indigenous populations.

There were large differences in maternal characteristics and rates of pregnancy complications other than diabetes between First Nations and non-Indigenous groups. However, the adjusted RRs showed that these factors hardly affected the associations of PGDM and
GDM with perinatal and postneonatal mortality in either population group.

We observed a marginally lower risk of perinatal death for GDM pregnancies in non-Indigenous infants, although this risk difference would be not statistically significant if accounting for multiple comparisons. The observation is, however, consistent with the reported reduced risk of perinatal death in diet-controlled GDM pregnancies. ${ }^{31}$ GDM is a transient hyperglycaemia that may occur in the second half of pregnancy. The relatively increased insulin resistance state in GDM may confer a greater capacity for maternal-fetal nutrient transfer to meet the demands for fetal growth and development ${ }^{32}$ - which may be somewhat 'beneficial' for fetal survival if hyperglycaemia is relatively well controlled. $^{33}$

Consistent with previous reports, ${ }^{8-17}$ the risk increases in adverse birth outcomes (preterm, LGA, birth defects and perinatal death) were observed to be less pronounced in GDM than PGDM pregnancies. The risk increase in LGA associated with GDM was greater in First Nations $(\mathrm{RR}=2.0)$ than non-Indigenous $(\mathrm{RR}=1.7)$ infants, indicating poorer glycaemia control (a common cause of $\mathrm{LGA}^{34}$ in First Nations mothers).

We confirmed the substantially elevated risk of birth defects in PGDM pregnancies ${ }^{9-13}$ in both First Nations and non-Indigenous infants. It remains uncertain whether GDM may increase the risk of birth defects. We did not observe any significantly increased risk of birth defects in 
GDM pregnancies in both First Nations and non-Indigenous groups.

\section{Strengths and limitations}

The main strength is the large population-based linked birth cohort. Our study has limitations. We did not have data on unmeasured risk factors including smoking, obesity, folic acid supplementation, preconception care and glycaemic control in diabetic pregnancies. Both smoking and obesity are known to be much more prevalent in First Nations versus non-Indigenous women. ${ }^{35}$ Glycaemic control in diabetic pregnancies is known to be worse in First Nations versus non-Indigenous populations. ${ }^{28}$ Differences in these and other unmeasured risk factors could partly account for the substantially higher perinatal and postneonatal mortality rates in First Nations versus non-Indigenous populations overall. ${ }^{21}$ However, the adjustment analyses indicated that the RRs of perinatal and postneonatal death comparing PGDM or GDM versus non-diabetic pregnancies within the First Nations or non-Indigenous group would be unlikely to have been affected by the differences in risk factors between the two groups. Our study is observational in nature, and could not determine whether diabetes is causal to any elevated risk of perinatal or postneonatal death. The study was based on a birth cohort in Quebec. More studies in other regions are required to understand the generalisability of the findings to First Nations (North American Indians) and other Indigenous populations.

\section{CONCLUSIONS}

Our study is the first to demonstrate that PGDM may increase the risk of perinatal death to a much greater extent in First Nations than in non-Indigenous populations, but may increase the risk of postneonatal death in non-Indigenous infants only. The observations suggest possibly differential impacts of PGDM on offspring's survival during the perinatal and postneonatal periods in First Nations versus non-Indigenous populations in Quebec. The underlying causes are unclear and deserve further studies. We speculate that population differences in the quality of glycaemic control in diabetic pregnancies and/or genetic vulnerability to hyperglycaemia's fetal toxicity may be contributing factors.

\section{Author affiliations}

${ }^{1}$ Obstetrics and Gynecology, Lunenfeld-Tanenbaum Research Institute, Mount Sinai Hospital, and Institute of Health Policy, Management and Evaluation, University of Toronto, Toronto, Ontario, Canada

${ }^{2}$ Obstetrics and Gynecology, Sainte-Justine Hospital Research Center, University of Montreal, Montreal, Québec, Canada

${ }^{3}$ Ministry of Education-Shanghai Key Laboratory of Children's Environmental Health, Shanghai Jiaotong University School of Medicine, Xinhua Hospital, Shanghai, China ${ }^{4}$ Prosserman Centre for Population Health Research, Lunenfeld-Tanenbaum Research Institute, Toronto, Ontario, Canada

${ }^{5}$ Epidemiology, University of Montreal Hospital Research Centre, Montreal, Quebec, Canada

${ }^{6}$ Obstetrics and Gynecology, Sainte-Justine Hospital Research Center, Montreal, Quebec, Canada
${ }^{7}$ Public Health Department, Cree Board of Health and Social Services of James Bay, Mistissini, Quebec, Canada

${ }^{8}$ Research Sector, First Nations of Quebec and Labrador Health and Social Service Commission, Wendake, Quebec, Canada

${ }^{9}$ Sainte-Justine Hospital Research Center, University of Montreal, Montreal, Québec, Canada

Acknowledgements The authors are indebted to the Indigenous and Northern Affairs Canada for providing the Indian Registration System membership database, and to the Régie de l'Assurance Maladie du Québec for providing the Maintenance et Exploitation des Données pour l'Étude de la Clientèle Hospitalière database for data linkage in the project. They are grateful to the Institut de la Statistique du Québec for providing access to the linked research database.

Contributors Z-CL, NA, JT and NG-LM conceived the study. LC, WJ-W, LX and Z-CL conducted the data analyses. LC and W-JW conducted the literature review and drafted the manuscript. All authors contributed in refining the analytic framework and data interpretation. All authors contributed in revising the article critically for important intellectual content, and approved the final version for publication.

Funding This work was supported by research grants from the Canadian Institutes of Health Research (grant numbers 155955 and 106521) and the National Natural Science Foundation of China (grant number 81571451).

Disclaimer The sponsors had no role in all aspects of the study including study design, analysis, manuscript preparation and decision for publication.

Competing interests None declared.

Patient consent for publication Not required.

Ethics approval The study was approved by the Research Ethics Committee of Sainte-Justine hospital, Montreal, Canada, in March 2011 (project number 3202).

Provenance and peer review Not commissioned; externally peer reviewed.

Data sharing statement The research database is housed at the Institut de la Statistique du Québec (ISQ). Request for access to the research database must be approved by the ISQ on a case-by-case basis. Contact the corresponding author (Z-CL) for assistance in data request to the ISQ.

Open access This is an open access article distributed in accordance with the Creative Commons Attribution Non Commercial (CC BY-NC 4.0) license, which permits others to distribute, remix, adapt, build upon this work non-commercially, and license their derivative works on different terms, provided the original work is properly cited, appropriate credit is given, any changes made indicated, and the use is non-commercial. See: http://creativecommons.org/licenses/by-nc/4.0/.

\section{REFERENCES}

1. Berger $\mathrm{H}$, Gagnon $\mathrm{R}$, Sermer $\mathrm{M}$, et al. Diabetes in Pregnancy. $J$ Obstet Gynaecol Can 2016;38:667-79.

2. Davis $B$, Bond D, Howat $P$, et al. Maternal and neonatal outcomes following diabetes in pregnancy in Far North Queensland, Australia. Aust N Z J Obstet Gynaecol 2009;49:393-9.

3. Dyck R, Klomp H, Tan LK, et al. A comparison of rates, risk factors, and outcomes of gestational diabetes between aboriginal and nonaboriginal women in the Saskatoon health district. Diabetes Care 2002;25:487-93.

4. Harris SB, Caulfield LE, Sugamori ME, et al. The epidemiology of diabetes in pregnant Native Canadians. A risk profile. Diabetes Care 1997;20:1422-5.

5. Moum KR, Holzman GS, Harwell TS, et al. Increasing rate of diabetes in pregnancy among American Indian and white mothers in Montana and North Dakota, 1989-2000. Matern Child Health J 2004;8:71-6.

6. Sellers EA, Dean HJ, Shafer LA, et al. Exposure to gestational diabetes mellitus: impact on the development of early-onset type 2 diabetes in Canadian First Nations and Non-First Nations Offspring. Diabetes Care 2016;39:2240-6.

7. Oster RT, King M, Morrish DW, et al. Diabetes in pregnancy among First Nations women in Alberta, Canada: a retrospective analysis. BMC Pregnancy Childbirth 2014;14:136.

8. Liu SL, Shah BR, Naqshbandi M, et al. Increased rates of adverse outcomes for gestational diabetes and pre-pregnancy diabetes in on-reserve First Nations Women in Ontario, Canada. Diabet Med 2012;29:e180-3.

9. Casson IF, Clarke CA, Howard CV, et al. Outcomes of pregnancy in insulin dependent diabetic women: results of a five year population cohort study. BMJ 1997;315:275-8. 
10. Penney GC, Mair G, Pearson DW. Scottish diabetes in pregnancy group. outcomes of pregnancies in women with type 1 diabetes in Scotland: a national population-based study. BJOG 2003;110:315-8.

11. Jensen DM, Damm P, Moelsted-Pedersen L, et al. Outcomes in type 1 diabetic pregnancies: a nationwide, population-based study. Diabetes Care 2004;27:2819-23.

12. Dunne FP, Avalos G, Durkan M, et al. ATLANTIC DIP: pregnancy outcome for women with pregestational diabetes along the Irish Atlantic seaboard. Diabetes Care 2009;32:1205-6.

13. Clausen TD, Mathiesen E, Ekbom P, et al. Poor pregnancy outcome in women with type 2 diabetes. Diabetes Care 2005;28:323-8.

14. Serehi AA, Ahmed AM, Shakeel F, et al. A comparison on the prevalence and outcomes of gestational versus type 2 diabetes mellitus in 1718 Saudi pregnancies. Int J Clin Exp Med 2015;8:11502-7.

15. Cundy T, Gamble G, Townend K, et al. Perinatal mortality in Type 2 diabetes mellitus. Diabet Med 2000;17:33-9.

16. Macintosh MC, Fleming KM, Bailey JA, et al. Perinatal mortality and congenital anomalies in babies of women with type 1 or type 2 diabetes in England, Wales, and Northern Ireland: population based study. BMJ 2006;333:177.

17. Son KH, Lim NK, Lee JW, et al. Comparison of maternal morbidity and medical costs during pregnancy and delivery between patients with gestational diabetes and patients with pre-existing diabetes. Diabet Med 2015;32:477-86.

18. Rodrigues S, Robinson E, Gray-Donald K. Prevalence of gestational diabetes mellitus among James Bay Cree women in northern Quebec. CMAJ 1999;160:1293-7.

19. Légaré G. Project of Diabetes Surveillance among the Cree of Efyou Istache. Cree Board of Health and Social Services of James Bay, Institut de National Santé Publique. 2004 http://www.inspq.qc.ca/ pdf/publications/317-DiabeteCri_Ang.pdf.

20. Luo ZC, Wilkins R, Platt RW, et al. Risks of adverse pregnancy outcomes among Inuit and North American Indian women in Quebec, 1985-97. Paediatr Perinat Epidemiol 2004;18:40-50.

21. Chen L, Xiao L, Auger N, et al. Disparities and Trends in Birth Outcomes, Perinatal and Infant Mortality in Aboriginal vs. NonAboriginal Populations: A Population-Based Study in Quebec, Canada 1996-2010. PLoS One 2015;10:e0138562.
22. Fair M, Cyr M, Allen AC, et al. An assessment of the validity of a computer system for probabilistic record linkage of birth and infant death records in Canada. The Fetal and Infant Health Study Group. Chronic Dis Can 2000;21:8-13.

23. $\mathrm{He} \mathrm{H}$, Xiao L, Torrie JE, et al. Disparities in infant hospitalizations in Indigenous and non-Indigenous populations in Quebec, Canada. CMAJ 2017;189:E739-E746.

24. American Diabetes Association. Gestational diabetes mellitus. Diabetes Care 2003;26(Suppl 1):S103-5.

25. Kramer MS, Liu S, Luo Z, et al. Analysis of perinatal mortality and its components: time for a change? Am J Epidemiol 2002;156:493-7.

26. Kramer MS, Platt RW, Wen SW, et al. A new and improved population-based Canadian reference for birth weight for gestational age. Pediatrics 2001;108:e35.

27. Turin TC, Saad N, Jun M, et al. Lifetime risk of diabetes among First Nations and non-First Nations people. CMAJ 2016;188:1147-53.

28. Dyck RF, Sidhu N, Klomp H, et al. Differences in glycemic control and survival predict higher ESRD rates in diabetic First Nations adults. Clin Invest Med 2010;33:390-7.

29. Brecher A, Tharakan T, Williams A, et al. Perinatal mortality in diabetic patients undergoing antepartum fetal evaluation: a casecontrol study. J Matern Fetal Neonatal Med 2002;12:423-7.

30. Dudley DJ. Diabetic-associated stillbirth: incidence, pathophysiology, and prevention. Obstet Gynecol Clin North Am 2007;34:293-307.

31. Karmon A, Levy A, Holcberg G, et al. Decreased perinatal mortality among women with diet-controlled gestational diabetes mellitus. Int J Gynaecol Obstet 2009;104:199-202.

32. Yamashita H, Shao J, Friedman JE. Physiologic and molecular alterations in carbohydrate metabolism during pregnancy and gestational diabetes mellitus. Clin Obstet Gynecol 2000;43:87-98.

33. Luo ZC, Simonet F, Wei SQ, et al. Diabetes in pregnancy may differentially affect neonatal outcomes for twins and singletons. Diabet Med 2011;28:1068-73.

34. Landon MB, Mele L, Spong CY, et al. The relationship between maternal glycemia and perinatal outcome. Obstet Gynecol 2011;117(2 Pt 1):218-24.

35. Oliveira AP, Kalra S, Wahi G, et al. Maternal and newborn health profile in a first nations community in Canada. J Obstet Gynaecol Can 2013;35:905-13. 